\title{
Influence of granule characteristics on fabrication of translucent alumina ceramics with high strength and reliability
}

\author{
Satoshi TANAKA, ${ }^{\dagger}$ Shota GOI and Zenji KATO \\ Department of Materials Science and Technology, Nagaoka University of Technology, \\ 1603-1 Kamitomioka-machi, Nagaoka, Niigata 940-2188, Japan
}

\begin{abstract}
Translucent alumina ceramics with high strength and reliability were fabricated through dry pressing of industry-grade granules and subsequent vacuum-sintering prior to hot isostatic pressing (HIP). The raw materials consisted of two types of granules, containing acrylic binder with and without $500 \mathrm{ppm} \mathrm{MgO}$. The internal structures of samples in each manufacturing step were evaluated by the liquid immersion method using an optical microscope. Large defects and their transitions were observed in the samples after each processing step. The fabricated ceramics had high relative density $(>99.6 \%)$ and very fine microstructures with grain sizes smaller than $1 \mu \mathrm{m}$. In the granule system with the binder non-uniformly distributed, interstices in the granules were observed in the powder compacts and samples after vacuum sintering. Alumina ceramics derived from the granule system with uniformly distributed binder and $\mathrm{MgO}$ additive exhibited high translucency with $50 \%$ in-line transmittance and strength greater than $\sim 700 \mathrm{MPa}$. This result suggests that characteristics of the granules considerably affect not only the packing structures in powder compacts but also the microstructure and properties of the sintered ceramics.
\end{abstract}

(C)2016 The Ceramic Society of Japan. All rights reserved.

Key-words : Alumina ceramics, Strength, Translucency, Hot isostatic pressing

[Received November 3, 2015; Accepted December 30, 2015]

\section{Introduction}

Advanced ceramics have been developed for various applications, and their microstructures have been studied and controlled to obtain functional properties. For example, translucent polycrystalline alumina with large grains and highly dense structures has been fabricated by using fine, high-purity ( $>99.99 \%)$ particles and a small amount of sintering additives such as MgO. ${ }^{1)-5 \text { ) }}$ Sintering has been conducted at temperatures greater than $1800^{\circ} \mathrm{C}$ under a controlled atmosphere containing $\mathrm{H}_{2}$. The use of finer primary particles promotes densification and elimination of pores during sintering. High-purity raw materials reduce the scattering of light due to contamination and prevent excess grain growth. Sintering additives such as $\mathrm{MgO}$ retard grain growth before densification and are effective at reducing the closed pores retained within the grains. A higher sintering temperature reduces grain boundaries due to grain growth up to several tens of microns. $\mathrm{A}_{2}$ atmosphere contributes to the easy diffusion of gas molecules from within the pores to the outside of the samples.

For optical use, ceramics are required to exhibit both translucency and good mechanical properties. ${ }^{6)-9)}$ Translucent alumina ceramics manufactured with the above mentioned processing method have not exhibited high strength, ${ }^{4), 5)}$ because grain growth at high temperature reduces the grain boundary but simultaneously causes the growth of large pores, which degrades mechanical properties. These large pores could not be completely removed. To achieve translucency and good mechanical properties simultaneously, other strategies for microstructure control should be considered. One solution is to control the processing for obtaining a very fine microstructure. ${ }^{6)-14)}$ Morinaga et al.

\footnotetext{
Corresponding author: S. Tanaka; E-mail: stanaka@vos. nagaokaut.ac.jp

* Preface for this article: Dol http://dx.doi.org/10.2109/jcersj2.124.P4-1
}

reported translucent alumina with submicron grains formed by injection molding and sintering with hot isostatic pressing (HIP). ${ }^{7)}$ Krell et al. reported the fabrication of high-strength transparent alumina through the wet-shaping approach combined with sintering under normal and HIP conditions at $1400^{\circ} \mathrm{C}^{8)-10)}$ For HIP, sintering is generally carried out under capsule-free condition by using pre-sintered samples that contain closed pores. Ikesue reported that for fabrication of YAG ceramics, the sample was presintered in vacuum prior to HIP. ${ }^{11)-13)}$ Shen et al. and other researchers reported the spark-plasma sintering of finegrained alumina. ${ }^{14)-23)}$ They reported that densification must be achieved by sintering at low temperatures.

From an industrial viewpoint, although many routes exist for forming and sintering, conventional forming and sintering processing are preferred. ${ }^{24}$ Granules are used in the industry primarily to achieve high productivity for dry packing as well as high and homogeneous packing density. However, the characteristics of granules have unfavorable effects on the powder processing and properties of ceramics. ${ }^{24)-28)}$ For example, hard, elastic granules tend to form large defects in green compacts as well as in sintered ceramics. ${ }^{28)}$ The binder also affects the structure through its distribution in the granules. PVA binder tends to segregate on the surface of the granules, leaving large processing defects in the compact after de-bindering. ${ }^{29)-31)}$

Direct observation of the structure during processing provides important information for controlling the structure of ceramics. ${ }^{32), 33)}$ Observations using the liquid immersion method (LIM) revealed that the interstices between granules and dimples of granules changed to large defects in the ceramics. ${ }^{33)}$ In the LIM, the granules or powder compact was immersed in an appropriate liquid having the same refractive index as that of the material. For alumina, methylene iodide or boromonaphthalene are suitable as the liquid, and it results in transparent alumina powder compacts. Therefore, the internal structure is observed with an optical 
microscope in transmission mode. Conversely, the internal structure of a sintered sample can be observed with an optical microscope in transmission mode by using a sample thinned to $100 \mu \mathrm{m}$ because such a sample would show translucency. ${ }^{34)-37)}$ Thus, large defects can be identified at each step during manufacturing.

This present study aimed at fabricating alumina ceramics with high reliability and high density through powder processing using industrial granules by focusing on structural changes during sintering. We used granules with a binder layer as well as granules with a thin binder layer and a small amount of sintering additive, $\mathrm{MgO}$.

\section{Experimental}

\subsection{Granules and their characterization}

Two types of commercial alumina granules were used as raw materials (DS31 and DS 90M, Taimei Chemical K. K., Japan). The size of the primary particles in both granules was $0.15 \mu \mathrm{m}$ as received from the supplier. DS31 contains an acrylic binder and DS $90 \mathrm{M}$ contains an acrylic binder and $50 \mathrm{ppm} \mathrm{MgO}$ as a sintering additive. Hereafter, DS31 and DS 90M are referred to as "granule B" and "granule M", respectively.

LIM was used to examine the internal structure of the granules. In this examination, the granules were immersed in bromonaphthalene (refractive index: 1.66) to make them transparent (refractive index of alumina: 1.77), and the internal structure was observed using an optical microscope in transmission mode (DX50, Olympus, Japan). A scanning electron microscope (JSM$5310 \mathrm{~L}$, JEOL, Japan) was used to examine the morphology and structure of the granules in detail. Micro-compaction equipment (MCTE-500, Shimadzu, Japan) was used to examine the compaction behavior of individual granules. For equilibration with moisture, the granules were placed in an ambient atmosphere for a day. A granule with a diameter of approximately $50 \mu \mathrm{m}$ was selected using the optical microscope for examination. The temperature was controlled at $20^{\circ} \mathrm{C}$. The tensile strength of the granule $\left(S_{\mathrm{t}}\right)$ was determined using the following equation proposed by Hiramatsu et al.:37)

$$
S_{\mathrm{t}}=2.8 P_{\mathrm{f}} / \pi D^{2},
$$

where $P_{\mathrm{f}}$ is the applied load at fracture and $D$ the average diameter of the granule.

The granules were uniaxially pressed in a die with double action by a universal mechanical testing machine (Autograph AG1, Shimadzu, Japan) at a crosshead speed of $1.0 \mathrm{~mm} / \mathrm{min}$. The test was performed at $20^{\circ} \mathrm{C}$ for both granules. A compaction curve was constructed from the load-displacement curve automatically recorded for each granule. The relative density (R.D.) of the compact was determined during the compression test by using the following equation:

$$
\text { R.D. }=100 w /(A h \rho),
$$

where $w$ is the weight of filled granules, $A$ is the base area of the compact (cross-sectional area of the pressing punch), $h$ is the height of the compact in the die, and $\rho$ is the theoretical density of alumina: $3.987 \times 10^{3} \mathrm{~kg} / \mathrm{m}^{3}$.

\subsection{Forming and sintering}

Granules were placed in a die $(45 \mathrm{~mm} \times 55 \mathrm{~mm})$ and pressed at $20 \mathrm{MPa}$; subsequently, they were cold isostatically pressed at 200 $\mathrm{MPa}$. After de-bindering at $500^{\circ} \mathrm{C}$ for $30 \mathrm{~min}$ in air, the compact was heated to $1350^{\circ} \mathrm{C}$ for $2 \mathrm{~h}$ in vacuum and then cooled to room temperature. The sample sintered in vacuum (1 Pa of air) was subsequently sintered at $200 \mathrm{MPa}$ and $1300^{\circ} \mathrm{C}$ for $2 \mathrm{~h}$ in an $\mathrm{Ar}$ atmosphere with HIP (Dr-HIP, Kobe steel, Japan).

\subsection{Characterization and mechanical properties}

LIM was applied to examine the internal structure of the powder compact, as with the granules. The powder compact, which was sliced and ground to a thickness of $100 \mu \mathrm{m}$, was immersed in bromonaphthalene, and the internal structure was observed with an optical microscope in transmission mode. The structure of the sintered body was also observed using an optical microscope in transmission mode. The samples were sliced, ground, and polished to a thickness of $100 \mu \mathrm{m}$ to make them translucent. To examine the eliminating process of pores by HIP, the $100-\mu \mathrm{m}$-thick sample heat treated in vacuum was treated with HIP. The transmitted image after HIP was compared with that before HIP. The microstructures of the samples were observed using a scanning electron microscope. Before observation, the polished samples were etched thermally at $1250^{\circ} \mathrm{C}$ for $30 \mathrm{~min}$ to clarify the grain boundary. The surfaces of samples were then coated by gold spattering.

The bending strength of the sintered body was measured by four-point bending tests at a cross-head speed of $0.5 \mathrm{~mm} / \mathrm{min}$ by using a universal mechanical testing machine. The samples were $3 \mathrm{~mm}$ thick, $4 \mathrm{~mm}$ wide, and $40 \mathrm{~mm}$ long.

\section{Results and discussion}

Figure 1 shows SEM micrographs of the primary particles. Figure 2 shows SEM and LIM micrographs of the granules used in this study. Granule B appears to have a spherical shape with a dimple. In the LIM micrograph, however, its internal structure is not uniform and shows a rim at the outline of the granule, which is the binder segregated around the surface. It appears dark because the binder scatters light owing to the large mismatch in the refractive indices. Granule M appears to have a non-spherical shape with a dimple. Its internal structure is uniform and shows a thin binder shell. The shape of granules may be influenced by the insufficient dispersion of ceramic particles in the slurry during spray drying.

Figure 3 shows a Weibull plot of the strength of a single granule, which was measured through the compaction test of a single granule. Granules $\mathrm{B}$ and $\mathrm{M}$ have average strengths of approximately 0.8 and $0.3-0.4 \mathrm{MPa}$, respectively. The binder shell on granule B, as shown in Fig. 2, may support the applied stress. This is why granule B had higher strength, and the data could be explained by the Weibull plots.

Figure 4 shows typical compaction curves for die pressing using these granules. The relative density of the compacted granules gradually increased with increasing applied stress for both granule systems. The compaction curves depended on the mechanical property of a single granule, as reported in previous

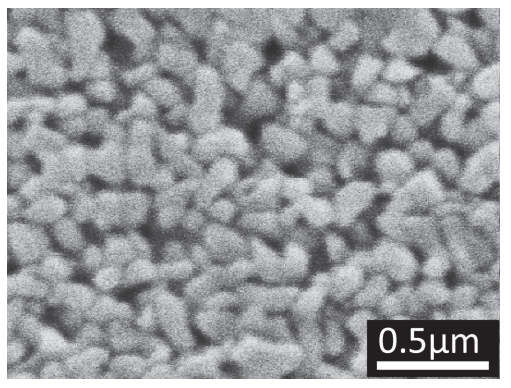

Fig. 1. SEM micrographs of primary particles. 

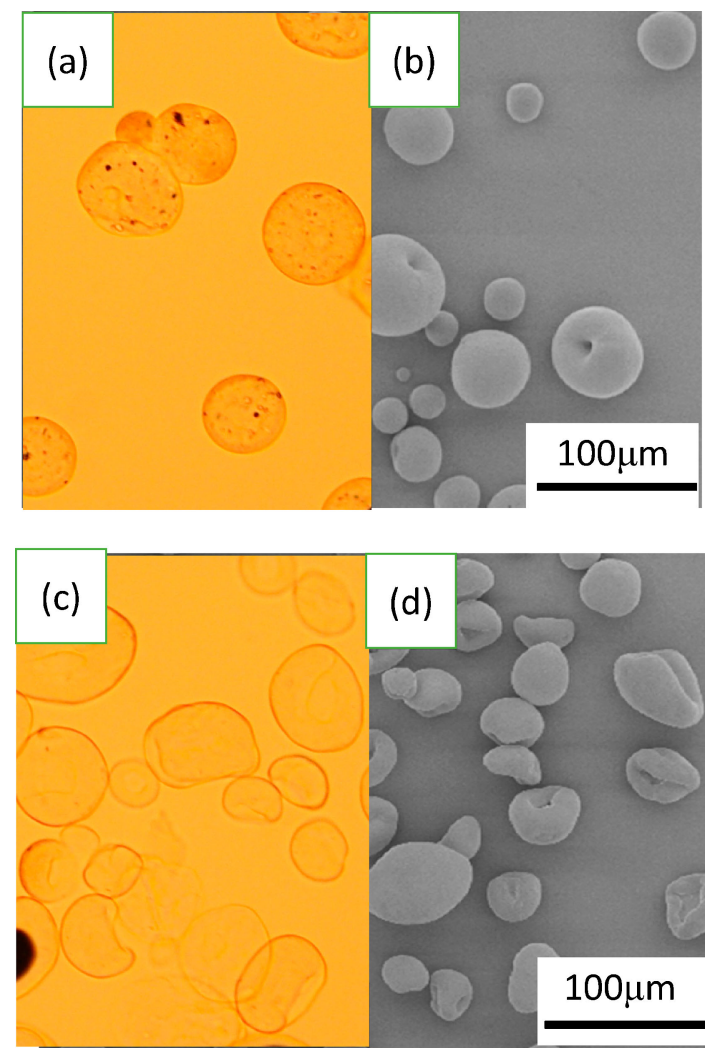

Fig. 2. SEM and LIM micrographs of (a), (b) granule B, (c), (d) granule M. (a), (c) LIM images and (b), (d) SEM images.

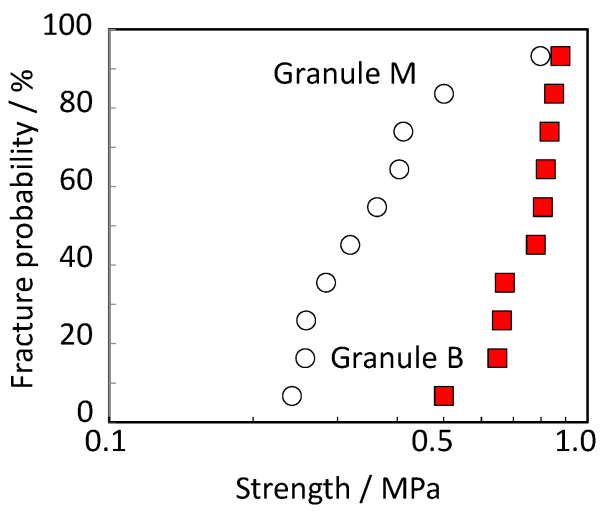

Fig. 3. Weibull plot of the strength of a single granule.

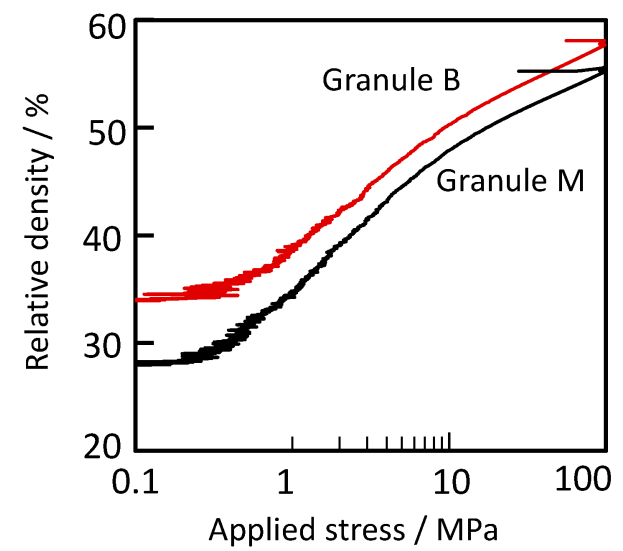

Fig. 4. Compaction curves for die pressing using the granules.
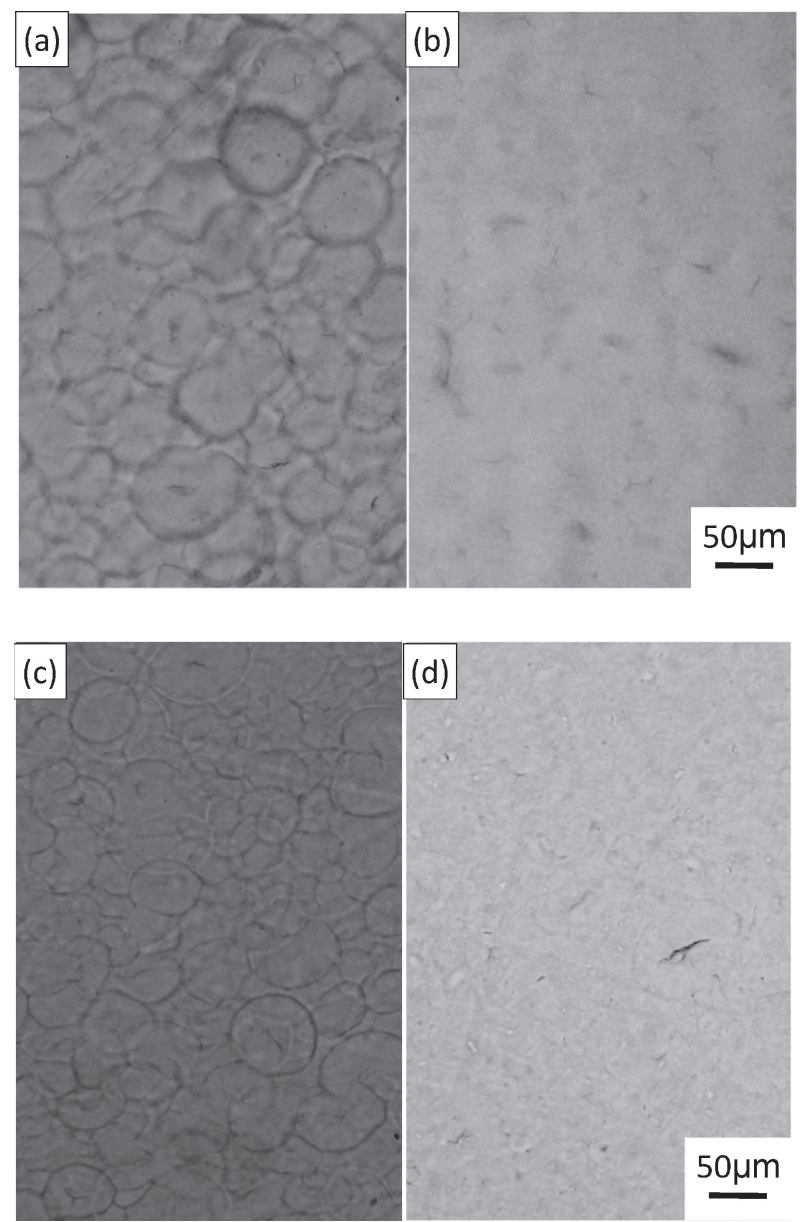

Fig. 5. Structure of powder compacts and the de-bindered samples examined with LIM using the optical microscope in transmission mode. (a) Sample made from granule B; (b), (a) after de-bindering. (c) Sample made from granule $\mathrm{M}$; (d), (c) after de-bindering.

studies. ${ }^{24), 27), 30)}$ The relative densities at low stress corresponded to the filled density in the metal die. Changes in slope appear at two locations, $\sim 1$ and $\sim 10 \mathrm{MPa}$, in each curve. The first change in slope corresponds to the starting point of granule deformation. The stress at the point at which there is a change in the slope of the curve for granule B is higher than that of granule M. This result is associated with the strength of a single granule. The second change corresponds to the starting point for particle rearrangement or densification within the granule in the compact body. A larger change in the relative density was observed in granule $\mathrm{M}$ than in granule $\mathrm{B}$ for an applied stress of up to 100 $\mathrm{MPa}$. The transfer of stress from the punch into the sample for the hard granule system is generally higher than that for the soft granule system. It is therefore possible for the hard granule system to deform well all over the sample.

Figure 5 shows the structure of the powder compacts and debindered samples examined with LIM using the optical microscope in transmission mode. The structure also depends on the characteristics of the granules. An inhomogeneous microstructure consisting of deformed granules is noted in the powder compacts made from both granules. In particular, the shapes and boundary of granules due to binder segregation are clearly noted in the powder compact made from granule B. The binder layer on the granule does not fit the neighboring granules even if granules are deformed at a high forming pressure. After de-bindering, a 

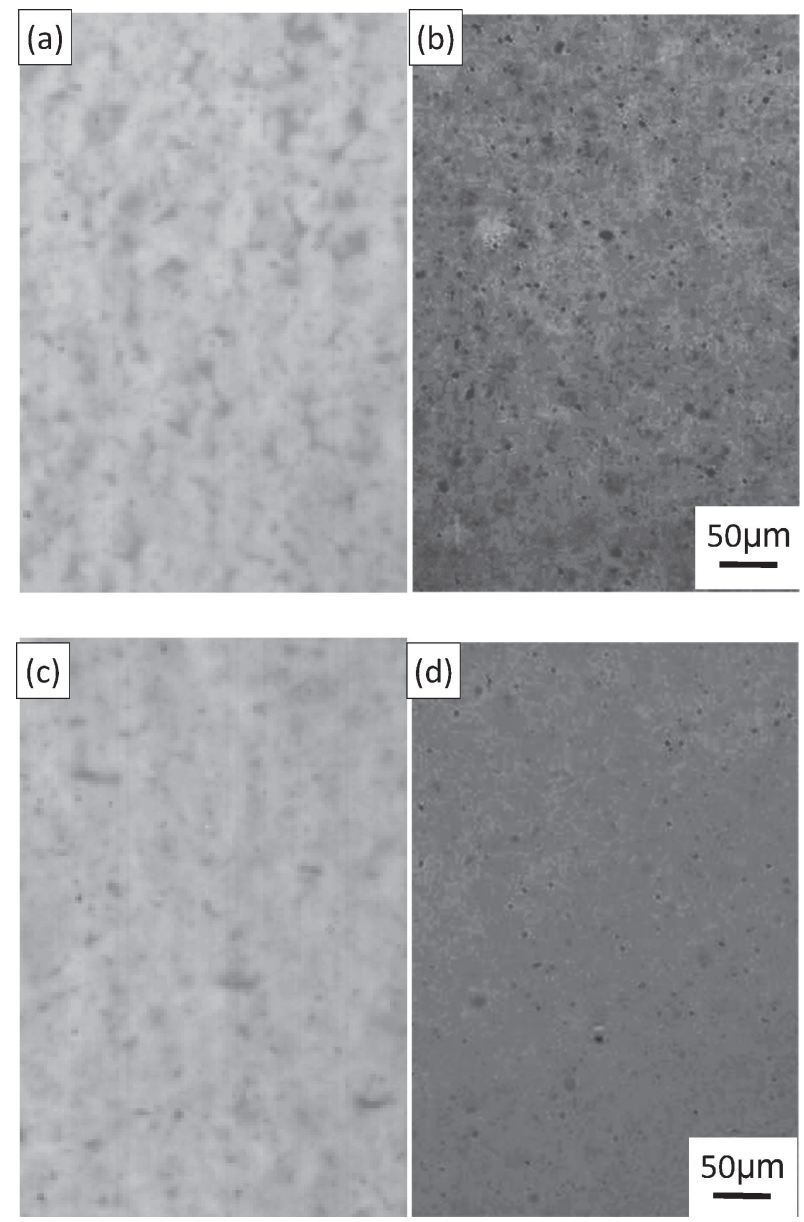

Fig. 6. Structures of vacuum-sintered samples and HIP-treated samples observed with the optical microscope in transmission mode using the thinned specimen $(200 \mu \mathrm{m})$. (a) Vacuum-sintered sample made from granule B; (b), (a) after HIP treatment. (c) Vacuum-sintered sample made from granule $\mathrm{M}$; (d), (c) after HIP treatment.

dimple is observed at the center of each granule. The frequency of dimples in the granule B system is greater than that in the granule $\mathrm{M}$ system.

Figure 6 shows the structures of the vacuum-sintered samples and HIP-treated samples observed using the optical microscope in transmission mode with a thinned specimen $(200 \mu \mathrm{m})$. Many large defects are observed as black shadows in the vacuumsintered samples. The relative density of samples is $95 \%$ for both systems. This suggests that sintering occurred easily in the dense part of the sample and that the loosely packed regions such as the granule dimple and boundary remained and developed into large defects. The large pores tend to gather the fine pores around themselves during sintering, according to classical sintering theory. ${ }^{38)}$ Conversely, many large defects appear to have been eliminated by HIP treatment. The relative densities of HIP-treated samples with granules B and $\mathrm{M}$ increased to 99.6 and $99.8 \%$, respectively. Grain growth occurred with HIP treatment. Defects of size $20-30 \mu \mathrm{m}$ are indicated as grey shadows in the internal structure. Many defects are observed in the granule B system.

However, the circular cloud-like pores of outer size $50-100 \mu \mathrm{m}$ are occasionally observed in both HIP-treated samples, as shown in Fig. 7. A crack can be seen at the center of the circle in Fig. 7(a). The gray shadow around the circle comprises very fine pores. For the granule M system, the cloud pores without center

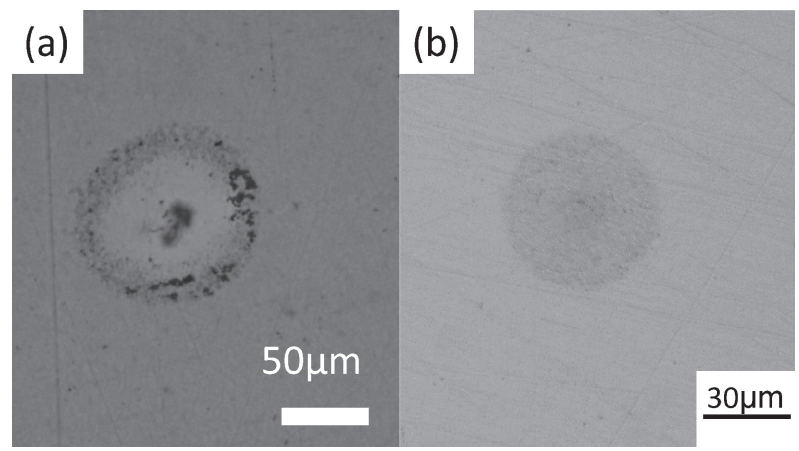

Fig. 7. Large defects on the surface of the samples made from (a) granule $\mathrm{B}$ and (b) granule $\mathrm{M}$.
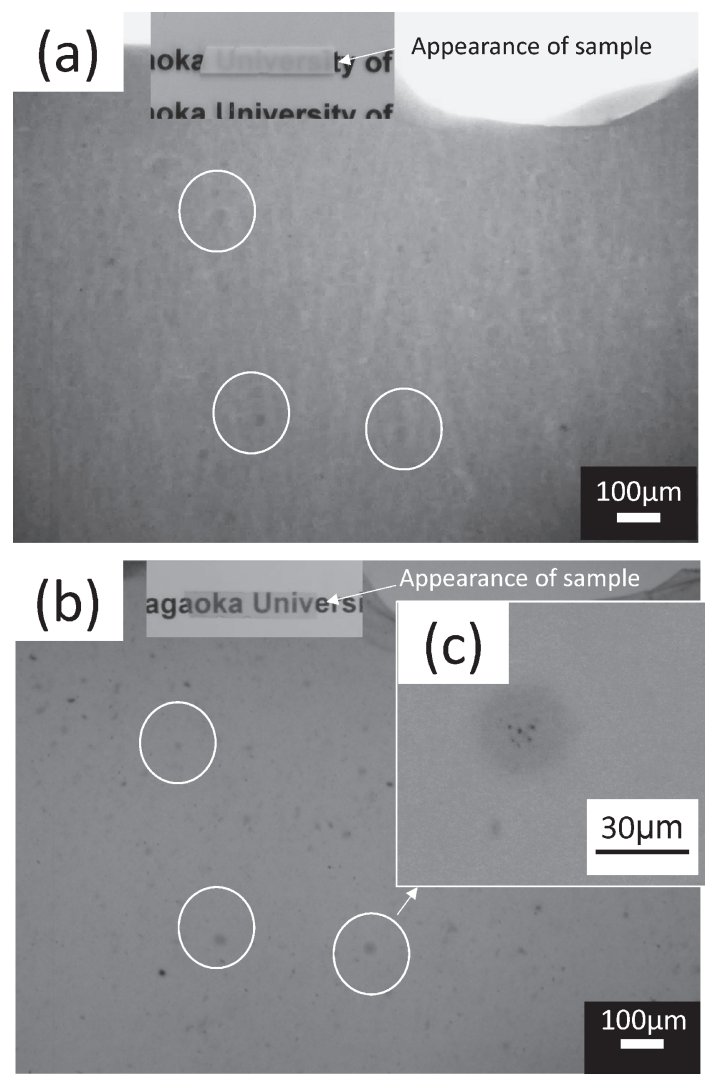

Fig. 8. Micrographs of samples made from granule $M$ (a) before and (b) after HIP treatment. (c) Expanded view of a large pore in (b). Appearance of samples are shown in (a) and (b).

defects were observed, as shown in Fig. 7(b).

To examine the effect of HIP on elimination of pores, particularly, to clarify the circular cloud-like pores, the structures at the same position before and after HIP were compared. Figure 8 shows micrographs taken using an optical microscope in transmission mode. An expanded view of the large pores after HIP is also shown. In Fig. 8, some large pores are observed at the same position after HIP treatment. The original pore $(<\sim 30 \mu \mathrm{m})$ in the sample remained after HIP treatment. In the expanded view of the large pores after HIP [Fig. 8(c)], the outlines of pores are ambiguous and similar to the structure shown in Fig. 7(b). This result suggests that cloud-like pores are formed on the eliminating large pores through HIP treatment. The grains near the large pores move, as in creep deformation, to close large pores owing 

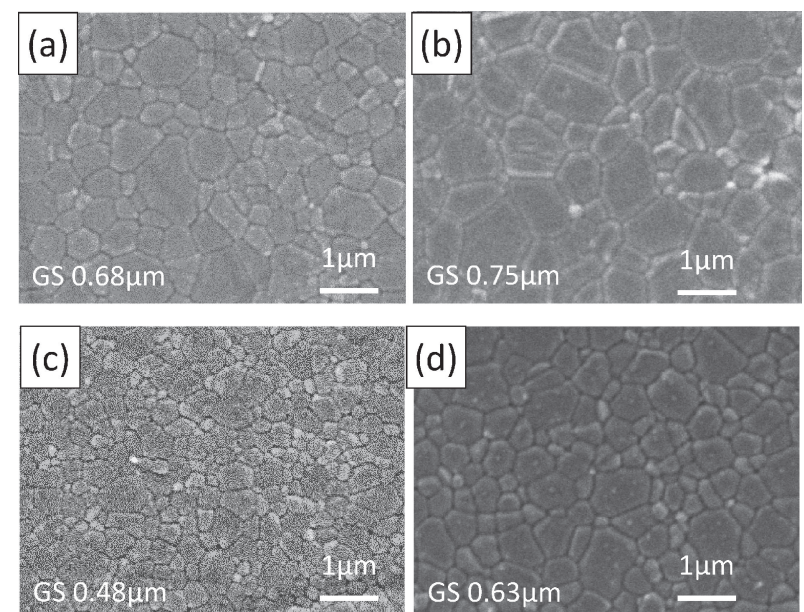

Fig. 9. Microstructures of (a) vacuum-sintered sample made from granule B; (b), (a) after HIP treatment; (c) vacuum-sintered sample made from granule M; (d), (c) after HIP treatment. These are SEM images for polished and thermally etched specimens.

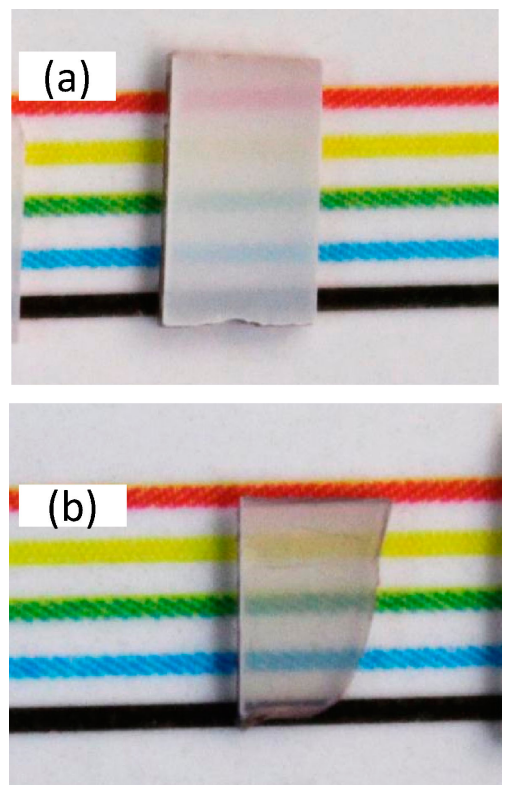

Fig. 10. Appearance of samples made from (a) granule B and (b) granule $\mathrm{M}$.

to HIP, because the size of the grains is very fine, less than $1 \mu \mathrm{m}$, as shown in Fig. 9. As a result, the traces of the moved grains are seen as cloud-like regions with fine pores.

Figure 9 shows the microstructures of both samples. The grain sizes in samples made from granules B and $\mathrm{M}$, which were measured by the intercept method, were 0.75 and $0.63 \mu \mathrm{m}$, respectively. The effect of $\mathrm{MgO}$ was seen in the higher densification and finer microstructure in samples made from granules $M$ than in samples made from granules B. Figure 10 shows the appearances of both samples. The thicknesses were $800 \mu \mathrm{m}$. The samples made from granules B and $\mathrm{M}$ show translucency, and the in-line transmittances of HIP-treated samples were 50 and $15 \%$, respectively, at a wavelength of $650 \mathrm{~nm}$, as shown in Fig. 11 .

Figure 12 shows the Weibull plots of the flexural strength of these ceramics. The average strength of ceramics using granule $\mathrm{M}$ was $691 \mathrm{MPa}$, which is greater than that of ceramics using granule $\mathrm{B}(565 \mathrm{MPa})$. In detail, although the maximum strength

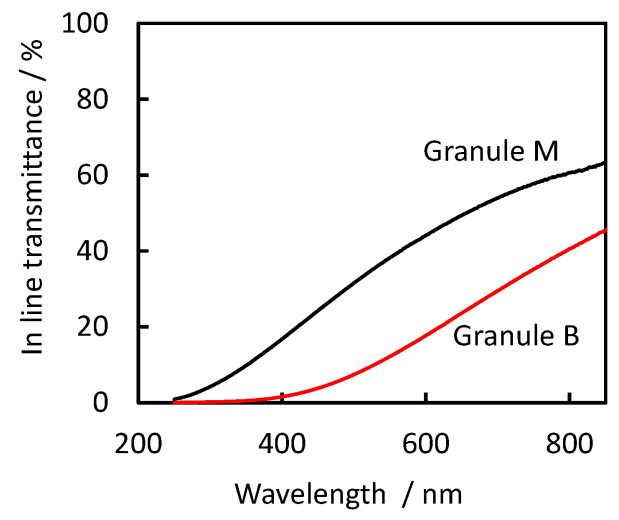

Fig. 11. In-line transmittance of samples made from (a) granule B and (b) granule $\mathrm{M}$.

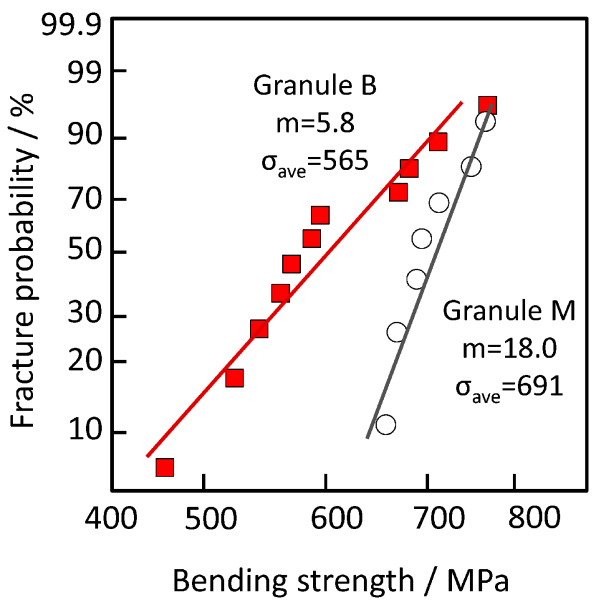

Fig. 12. Weibull plots of the flexural strength of ceramics made from (a) granule $\mathrm{B}$ and (b) granule $\mathrm{M}$.

of the granule $\mathrm{M}$ system is the same as that of the granule B system, the minimum strength of the granule B system is considerably weaker. The Weibull modulus of the sample made from granule $\mathrm{M}$ is 18.0 , whereas that of the sample made from granule $\mathrm{B}$ is $\sim 6$. While HIP treatment under a pressure of $200 \mathrm{MPa}$ at $1300^{\circ} \mathrm{C}$ was effective for reducing the size of large defects, the results of the very weak strength of the sample made from granule B suggest the limitation of pore size. Particularly, as shown in Fig. 6(a), it seems that a few crack-like defects of size $50-100 \mu \mathrm{m}$ are present in the sample made from granule B with vacuum-sintering. Those defects may remain even after HIP.

Here, the equivalent crack length is calculated from the strength value according to the Griffith equation:

$$
\sigma=\frac{K_{\mathrm{Ic}}}{\sqrt{\pi a}}
$$

where $\sigma$ is the fracture stress, $K_{\mathrm{Ic}}$ is the fracture toughness, and $a$ is half of the length of a crack. The equivalent crack length, $2 a$, decreases in inverse proportion to the square of the strength. If the strengths are 400 and $700 \mathrm{MPa}$ and fracture toughness is $3.5 \mathrm{MPam}^{0.5}$, the equivalent crack lengths are $\sim 49 \mu \mathrm{m}$ and $\sim 16$ $\mu \mathrm{m}$, respectively. In the sample made from granule $\mathrm{M}$ of strength $700 \mathrm{MPa}$, defects of size $\sim 20 \mu \mathrm{m}$ were observed in Fig. 6(d). Conversely, large defects of size $\sim 50 \mu \mathrm{m}$ are shown in Fig. 7(a). These pores may govern the mechanical strength. If this property is to be improved further, the pore size in the powder compact 
must be reduced by controlling the granule characteristics.

\section{Conclusions}

Translucent alumina ceramics with high strength and reliability were fabricated by dry-pressing and subsequent sintering with HIP. The structure was observed during manufacturing by using an optical microscope in transmission mode. In the experiment, industrial granules containing an acrylic binder and a small amount of $\mathrm{MgO}$ were used as the raw material. The characteristics of the granules govern the final structures from the packing structure in the powder compact to the structure of sintered ceramics. In the granule system with binder, granule B, processing defects such as dimples and interstices of granules were remarkably observed in the powder compact and samples after vacuum sintering. Even after HIP treatment, many large defects remained in the sample. Conversely, the size of large pores in the granule system with the binder and the sintering additive $\mathrm{MgO}$, granule $\mathrm{M}$, are small compared with that of granule $\mathrm{B}$. A very thin binder layer and $\mathrm{MgO}$ additive in granules play an important role in structure formation. We achieved $50 \%$ in-line transmittance, strength of $\sim 700 \mathrm{MPa}$, and Weibull modulus of 18 in the ceramics formed with granule $\mathrm{M}$. These properties should be improved further by controlling the granule characteristics.

Acknowledgement We would like to thank Emeritus Prof. Keizo Uematsu for discussion. This work was partly supported by Program for High Reliable Materials Design and Manufacturing in Nagaoka University of Technology.

\section{References}

1) R. L. Coble, J. Appl. Phys., 32, 787-792 (1961).

2) W. H. Rhodes, D. J. Shllers and T. Vasilos, J. Am. Ceram. Soc., 58, 31-34 (1975).

3) F. F. Lange, J. Am. Ceram. Soc., 72, 3-15 (1989).

4) G. C. Wei and W. H. Rhodes, J. Am. Ceram. Soc., 83, 1641$1648(2000)$.

5) X. J. Mao, S. W. Wang, S. Shimai and J. K. Guo, J. Am. Ceram. Soc., 91, 3431-3433 (2008).

6) X. Jin, L. Gao and J. Sun, J. Am. Ceram. Soc., 93, 1232-1236 (2010).

7) K. Hayashi, O. Kobayashi, S. Toyoda and K. Morinaga, Mater. Trans., JIM, 32, 1024-1029 (1991).

8) A. Krell and P. Blank, J. Eur. Ceram. Soc., 16, 1189-1200 (1996) HIP.

9) A. Krell, P. Blank, H. Ma, T. Hutzler, M. P. B. van Bruggen and R. Apetz, J. Am. Ceram. Soc., 86, 12-18 (2003).

10) R. Apetz and M. P. B. Bruggen, J. Am. Ceram. Soc., 86, 480 486 (2003).

11) A. Ikesue, I. Furusato and K. Kamata, J. Am. Ceram. Soc., 78, 225-228 (1995).

12) A. Ikesue and K. Kamata, J. Am. Ceram. Soc., 79, 1927-1933
(1996).

13) U. Peuchert, Y. Okano, Y. Menke, S. Reichel and A. Ikesue, J. Eur. Ceram. Soc., 29, 283-291 (2009).

14) Z. Shen, M. Johnsson, Z. Zhao and M. Nygren, J. Am. Ceram. Soc., 85, 1921-1927 (2002).

15) H. Mizuda, K. Oda, Y. Shibasaki, M. Maeda, M. Machida and K. Ohshima, J. Am. Ceram. Soc., 75, 469-473 (1992).

16) J. Echeberria, J. Trazona, J. Y. He, T. Butler and F. Castro, J. Eur. Ceram. Soc., 22, 1801-1809 (2002).

17) B. Kim, K. Hiraga, K. Morita and H. Yoshida, J. Eur. Ceram. Soc., 29, 323-327 (2009).

18) B. Kim, K. Hiraga, K. Morita, H. Yoshida, T. Miyazaki and Y. Kagawa, Acta Mater., 57, 1319-1326 (2009).

19) B. Kim, K. Hiraga, K. Morita and H. Yoshida, Scr. Mater, 57, 607-610 (2007).

20) D. T. Jiang, D. M. Hulbert, U. Ansilmi-Tamburini, T. Ng, D. Land and A. K. Mukherjee, J. Am. Ceram. Soc., 91, 151-154 (2008).

21) S. Grasso, C. F. Hu, G. Maizza, B. N. Kim and Y. Sakka, J. Am. Ceram. Soc., 94, 1405-1409 (2011).

22) M. Stuer, Z. Zhao, U. Aschauer and P. Bowen, J. Eur. Ceram. Soc., 30, 1335-1343 (2010).

23) K. H. Brosnan, G. L. Messing and D. K. Agrawal, J. Am. Ceram. Soc., 86, 1307-1312 (2003).

24) J. S. Reed, "Principle of Ceramics Processing", second edition, John Wiley and Sons, Inc. New York (1995) pp. 395-449.

25) C. W. Nies and G. L. Messing, J. Am. Ceram. Soc., 67, 301304 (1984).

26) W. J. Walker, Jr., J. S. Reeds and S. K. Verma, J. Am. Ceram. Soc., 82, 50-56 (1999).

27) W. J. Walker, Jr., J. S. Reeds and S. K. Verma, J. Am. Ceram. Soc., 82, 1711-1719 (1999).

28) H. Takahashi, N. Shinohara, M. Okumiya, K. Uematsu, J. Tsubaki, Y. Iwamoto and H. Kamiya, J. Am. Ceram. Soc., 78, 903-908 (1995).

29) S. Tanaka, Y. Saito, K. Tanaka, N. Uchida and K. Uematsu, Key Eng. Mater., 264-268, 189-192 (2004).

30) S. Tanaka, C. C. Pin and K. Uematsu, J. Am. Ceram. Soc., 89, 1903-1907 (2006).

31) S. Tanaka, J. Ceram. Soc. Japan, 114, 141-146 (2006).

32) K. Uematsu, J. Y. Kim, M. Miyashita, N. Uchida and K. Saito, J. Am. Ceram. Soc., 73, 2555-2557 (1990).

33) K. Uematsu, Powder Technol., 88, 291-298 (1996).

34) Y. Miyashita, J. Y. Kim, Z. Kato, N. Uchida and K. Uematsu, J. Ceram. Soc. Japan, 100, 1357-1360 (1992).

35) K. Uematsu, M. Sekiguchi, J. Y. Kim, K. Saito, Y. Mutoh, M. Inoue, F. Fujino and A. Miyamoto, J. Mater. Sci., 28, 17881792 (1993).

36) Y. Zhang, M. Inoue, N. Uchida and K. Uematsu, J. Mater. Res., 14, 3370-3374 (1999).

37) Y. Hiramatsu, Y. Oka and H. Kiyama, J. Miner. Eng. Japan, 81, 1024-1430 (1965).

38) D. Kingery, "Introduction to Ceramics", second edition, John Wiley and Sons, Inc. (1976) pp. 448-515. 